\section{Successful closure of an esophagopericardial fistula with an over-the-scope clip}

Esophageal perforation is a rare complication of transesophageal echocardiography with an incidence of $0.01 \%-0.3 \%$ [1].

In October 2011, a 56-year-old woman underwent a lung transplant for nonspecific interstitial pneumonia. Postoperatively, whilst receiving triple immunosuppression, her C-reactive protein (CRP) started to rise steadily and she developed atrial fibrillation, septic shock, and renal insufficiency. After 26 days, she was found to have a pneumopericardium on computed tomography (CT; $\bullet$ Fig. 1). An upper gastrointestinal endoscopy performed after a bronchopericardial fistula had been excluded showed a fistula in the middle third of the esophagus ( $\bullet$ Fig. 2 a). As this was close to the left atrium, it was suspected that a transesophageal echocardiogram was the cause. The pericardium was fenestrated and a drain inserted. After this, a self-expanding metal stent
(SEMS) was deployed (Ultraflex, $12 \mathrm{~cm} \times$ 23/28 mm; Boston Scientific, Natick, Massachusetts, USA).

Having recovered from the septic shock, the patient underwent removal of the stent 2 weeks later. Because the perforation was still present, an over-the-scope clip (OTSC; 11/3a; Ovesco Endoscopy, Tübingen, Germany) was applied ( $\mathbf{F i g . 2 b}$, c). Closure of the perforation was demonstrated by a CT scan that showed no leakage of oral contrast ( $\bullet$ Fig. 3 ). After 6 days the pericardial drain was removed and ongoing closure was confirmed by a further CT scan with oral contrast. After 4 weeks the patient was receiving oral nutrition with no signs of inflammation or pericardial effusion.

The outcome of esophageal perforation is strongly influenced by early diagnosis and treatment. Small lesions can be managed conservatively, but nowadays most
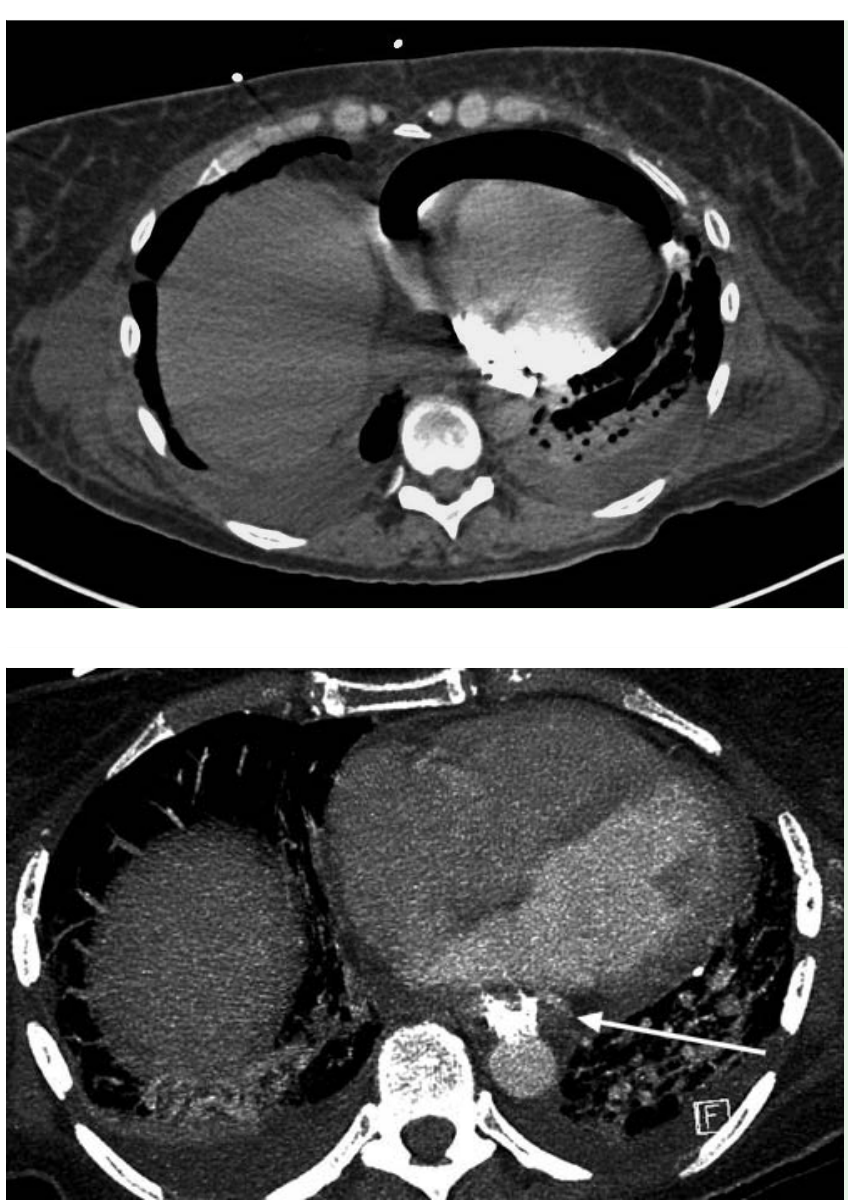

perforations are initially treated by insertion of covered SEMSs [2], although nearly half of the patients will need a second stent inserted subsequently. The insertion of a percutaneous, thoracoscopic, or even open surgical drain into the mediastinum improves the likelihood of sealing the perforation because it empties the cavity of secretions and provides an extrinsic cover for the perforation site [3]. Successful closure of esophageal perforations with endoclips has been previously reported $[4,5]$, as has the successful sealing of leaks with OTSCs [6].

Endoscopy_UCTN_Code_TTT_1AO_2AI

\section{Competing interests: None}

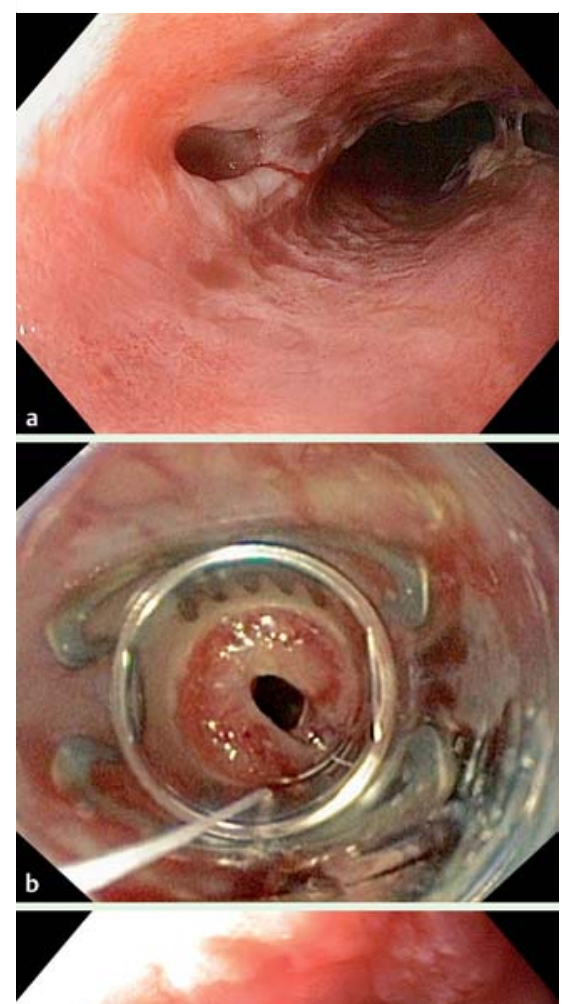

Fig. 1 Contrast-enhanced computed tomography (CT) scan in a 56-year-old female lung transplant recipient showing a pneumopericardium.

Fig. 3 Computed tomography (CT) scan after oral intake of contrast medium showing the over-the-scope clip (OTSC) in place (arrow) with no evidence of contrast leakage, which confirms closure of the fistula. 


\section{Gubler, P. Bauerfeind}

Department of Gastroenterology and Hepatology, University Hospital of Zurich, Switzerland

\section{References}

1 Hilberath JN, Oakes DA, Shernan SK et al. Safety of transesophageal echocardiography. J Am Soc Echocardiogr 2010; 23: 1115-1127, quiz 1220-1221

2 D'Cunha J, Rueth NM, Groth SS et al. Esophageal stents for anastomotic leaks and perforations. J Thorac Cardiovasc Surg 2011; 142: $39-46$
3 Johnsson E, Lundell L, Liedman B. Sealing of esophageal perforation or ruptures with expandable metallic stents: a prospective controlled study on treatment efficacy and limitations. Dis Esophagus 2005; 18: $262-266$

4 Qadeer MA, Dumot JA, Vargo JJ et al. Endoscopic clips for closing esophageal perforations: case report and pooled analysis. Gastrointest Endosc 2007; 66: 605-611

5 Shimizu Y, Kato M, Yamamoto J et al. Endoscopic clip application for closure of esophageal perforations caused by EMR. Gastrointest Endosc 2004; 60: 636-639

6 Pohl J, Borgulya M, Lorenz D et al. Endoscopic closure of postoperative esophageal leaks with a novel over-the-scope clip system. Endoscopy 2010; 42: 757-759
Bibliography

Dol http://dx.doi.org/

10.1055/s-0031-1291692

Endoscopy 2012; 44: E194-E195

(C) Georg Thieme Verlag KG

Stuttgart · New York

ISSN 0013-726X

\section{Corresponding author}

\section{Gubler, MD}

Division of Gastroenterology and Hepatology Department of Internal Medicine

University Hospital of Zurich

Rämistrasse 100

Zurich 8091

Switzerland

Fax: +41-44-2554474

christoph.gubler@usz.ch 